\title{
Selection of PPP Projects in China Based on Government Guarantees and Fiscal Risk Control
}

\author{
Yong Jiang ${ }^{1}$ \\ ${ }^{1}$ School of English for International Business, Guangdong University of Foreign Studies, Guangzhou, China \\ Correspondence: Yong Jiang, School of English for International Business, Guangdong University of Foreign Studies, \\ Room 317, No.3 Teaching Building, 2\# North Baiyun Ave., Guangzhou 510420, China. Tel: 86-139-2957-1649. \\ E-mail: jiangyong@gdufs.edu.cn
}

Received: December 13, 2016

Accepted: December 29, 2016 Online Published: December 30, 2016

doi:10.5430/ijfr.v8n1p99

URL: http://dx.doi.org/10.5430/ijfr.v8n1p99

\begin{abstract}
Public-Private Partnership (PPP) is an effective investment channel for government to provide public services. PPPs have the advantage of transferring some project risk to the private sector. They also imply that the public sector should establish appropriate laws and regulations to enable government departments to effectively avoid the emergence of new fiscal risks, which may affect the sustainability of fiscal budgets. This paper expounds the fiscal risks implied by PPP projects in China and the status of government guarantees in various forms of PPP projects; chance-constrained goal-programming (CCGP) is used to simulate government project selection under budget and risk control constraints. The analysis takes fiscal space, the expected costs and benefits of government guarantees, and the possibility of excess government subsidies into consideration. Constrained by fiscal risk minimization and budget limitations, PPP projects with government guarantees can maximize social-economic net present value and simultaneously optimize welfare. The paper also puts forward corresponding policy recommendations based on the research findings.
\end{abstract}

Keywords: government guarantee, fiscal risk, public-private partnership, risk control

The PPP model is generally regarded as a series of legal and financial arrangements between government and social capital for the provision of public services and the construction of public facilities. This arrangement transfers the risk of demand to the private sector while ensuring the delivery of public services. The public sector uses PPP contracts to define those long-term tasks that allow the private sector to receive long-term compensation from the public sector. In this arrangement, government departments have succeeded in transferring the traditional provision of public services to the private sector, including the provision of public services (for example, medical care, prisons, government buildings, communication networks, roads and railways, etc.) and public goods (such as tap water, heating supply, sewage, garbage disposal, etc.). Some public services and products can be offered in a "user-paid" mode, but public projects such as infrastructure and defense spending require constant government support. From this perspective, the efficient use of government funds and the participation of social capital are important. The PPP model aims to use market mechanisms to rationally distribute risk and improve the quantity, quality and efficiency of public goods and services. The term "social capital" refers to domestic and foreign legal entities that have established a modern enterprise system, but does not include government-owned financing platform companies or other state-owned enterprises (SOEs).

Fiscal risks refer to the possibility of various potential hazards to government investment activities and the social economic condition induced from government's inappropriate public financial activities or actions. If specific actions (i.e., public investment activity) of a particular actor (such as government, other public organizations, etc.) trigger fiscal risk, a significant way to reduce or avoid these risks is to change the scope, methods and models of such behavior. In the PPP model, the arrangements of public funds are not dominant and projects are largely supported by social capital. As such, the intention of the private sector is to gain benefits from the operation processes of projects. The government's fiscal risk is embodied as a hidden risk, because the nature of PPP projects is public with government's participation a priority. The government's public service provision responsibility is inherent in its functions. Therefore, the financial responsibility of government is unavoidable if a PPP project is mismanaged in cost and payment. Importantly, PPP projects are mostly large-scale, long-term projects typically spanning multiple 
fiscal budget years. While the time span of government budget control is relatively short, contradictions between the long-term funding arrangements of PPP projects and government's short-term budget cycle are notable.

\section{Fiscal Risks and Government Guarantees in the PPP Model}

The PPP model transfers some of project risks to the private sector, or the social capital investment provider, but its special nature also determines the existence of fiscal risks and potential problems. Financial institutions, such as the International Monetary Fund, have recently begun to focus their research on the fiscal risks of the PPP model, which can effectively use extra-budgetary funds beyond the limits of fiscal resources but can also result in high medium- or long-term costs (Bernardin et al., 2007). This liability is a long-term payment responsibility and contingent liability rather than a real liability (Wibowo and Wilhelm, 2014). In many countries, it is not a compulsory task for governments to systematically measure the size and impact of such liabilities, so government guarantees tend to stimulate a rapid expansion of PPP projects (MoF-China, 2014). To increase rationality, the impact of government guarantees on projects should therefore be taken into consideration in the PPP project decision-making process, (Yuan, et al., 2010).

There are few articles in the literature that discuss fiscal risks in the PPP model and there is even less research on how to evaluate project investment benefits that have government guarantees (Zhang, et al., 2016). It is of great practical significance, therefore, to conduct further studies on the long-term nature of PPP contracts and government's implicit and contingent liabilities. Public sector PPP project risks cannot be transferred to the private sector, based on public service provision characteristics and the institutional constraints of long-term budget mechanisms. Therefore, the PPP model has its own characteristics with potential fiscal risks. In the context of incomplete fiscal budgeting and public accounting systems in China, the institutional background of PPP projects includes:

1) Firstly, the private sector has a better understanding of project financing risk-sharing systems than the public sector and asymmetric information makes the private sector more discursive in negotiations. Public sectors undertake obligations for the provision of public services, even if the private sector is responsible for the construction and operation of public projects. Government's ultimate responsibility cannot be changed and it must maintain normal and continuous provision of public services. The degree of risk is closely related to the type of PPP project and the terms of government's commitment.

2) Secondly, the public sector's ability to undertake risks demonstrates the government's continuous commitment to the public, so the risk-sharing model differs from that of the private sector. In general project financing, imbalanced risk-sharing affects the project process and maximizes the benefits of all participating parties. But, in PPP projects, risks undertaken by the public sector do not affect the private sector because the risk of government's commitment, in the form of guarantees, will eventually transfer to the public sector.

3) Thirdly, since the government procurement process is fair and transparent, project selection must be processed within the framework of a formal procurement process; in contrast, private sector investments are more flexible. Recently, more stringent requirements on tendering processes in the public sector make project financing more transparent. Government departments in the bidding process cannot be arbitrarily changed, but the bidders may exploit loopholes or use information asymmetry to obtain the rights of PPP project construction, so government must prepare tender documents cautiously in order to prevent risk.

4) Fourthly, government's budget system is short-term and most of the government's appropriations are executed on an annual basis. During the pre-tender and construction period, government takes almost no payment responsibility for PPP projects, so the administration is not exposed to over-expenditure project risk. Most of the PPP expenditures cannot, therefore, be reflected in the short-term budget and the traditional government procurement budgetary mechanisms are no longer applicable to PPP projects. Government may select inefficient projects constructed in the form of a PPP model, which may result in an imbalance of cost and income in the late stages of PPP projects.

In a PPP model, government is confronted by the following main fiscal risks:

First, the risk of project selection. It is important for governments to make a preliminary selection of the PPP project. This "Value for Money" (VFM) method and the return on social capital are used to calculate the project's return. The choice of projects and government's short-term budget are not directly linked to the government's fiscal status so no government responsibility exists in the pre-payment period. Projects are therefore regarded as "zero cost". If the method of selecting a PPP project is used improperly, government may choose inefficient projects. If the cost of these projects is high and the social-economic benefits are limited, the budget responsibility of government will be 
augmented in the latter period creating an unaffordable financial burden for the follow-up government.

Second, the risk resulting from the authority's approval. This risk category mainly refers to the risks arising from various approval procedures due to delays or excessive restrictions. The risks, which are associated with various environmental permits and local government project approvals or authorizations, will substantially increase the overall cost of a PPP project. Because of the high degree of uncertainty and risk premiums associated with such costs, government faces high costs in transferring such risks to the private sector. If these risks are undertaken by the private sector, government would have to accept the changes in the various approval procedures resulting from the changing external conditions. However, the private sector would tend to derive economic rents in these activities. Therefore, it is necessary for government to determine the appropriate approval procedures and clear implementation steps before bidding on projects. When the contract is completed, the government will undertake the additional costs resulting from any changes.

Third, the risk of an uncontrollable project. Errors in project design can lead to the inefficient operation of a project, increasing budget costs. As such, cost control and low efficiency may be derived from the initial design of PPP projects. PPP contracts that typically contain flexible clauses to accommodate changing conditions increase costs and bring a heavy burden onto government departments.

Fourth, demand risk. After the completion of a project, government is exposed to the risk of an insufficient demand for public service provisions. If the project contract stipulates that public and private sectors share the financial responsibility arising from public demand, government will face the obvious fiscal risk of a greater government payment obligation than planned. Therefore, such risks must be taken into account in the planning stage, the preparation process of tender documents, the evaluation process of tender documents and the overall implementation stage of the PPP project contract, potentially minimizing the probability of risk.

Fifth, the risk of renegotiation. Asymmetry of information increases risk potentially requiring government to renegotiate, with the private sector, the whole process of contract implementation. From a technical perspective, renegotiation is an important tool to overcome contract deficiencies, but excessive renegotiation opportunities may lead to opportunistic behaviors of the concessionaire. As such, contracts should clearly state under what circumstances the renegotiations should be restarted and which principles the renegotiations should follow. Renegotiating risk is often accompanied by the risk of bankruptcy; if the franchisor goes through bankruptcy, government has to find a new partner or take over the project directly. Such costs must be taken into account in PPP contracts, which should specify the terms of how the government transfers PPP projects to other partners and related procedures.

PPP fiscal risks can be classified into following four types: (1) Risks that the government is directly responsible for, such as the risk of policy instability, risk of changes in relevant laws and regulations, future spending commitments, financing risks, and so on. (2) Project risks allocated to the government such as, government intervention and default risk, the risk of extended government approval, project bidding risk, feasibility demonstration risk, the risk of residual value of assets, the risk of renegotiation, force majeure, and so on. (3) Government guarantees, which include credit guarantees, material supply and price guarantees, minimum income guarantees, the guarantees of exchange rates, interest rates, inflation, and so on. (4) The risk of contingent liabilities such as, environmental risks, private sector bankruptcy risk, etc. The two most significant risk factors, among these four categories, are the government guarantee risk factor (\#3) followed by the project risks allocated to the government (\#2).

In addition, from the perspective of the relationship between central and local governments, the involvement of local governments in PPP projects may lead to risk spillover effects. The operation of PPP projects is complex, requiring improvement in their system design and technical level. Local governments believe that the fiscal risk of PPP projects with insufficient funds will be undertaken by the central government, so local governments will vigorously expand PPP projects under inappropriate institutional conditions. If governments provide corresponding guarantees to PPP projects, the project company tends to ignore the potential risks and efficiency of a project, which results in the increase of fiscal risk for local government and a risk premium for the entire government financial system.

Government guarantees, which is one of the ways that government can provide financial support for PPP projects, refer to the commitment that government, as the guarantor, provides compensation to the secured party when the guaranteed rights and interest is lower than the committed level. The secured party here refers to a private investor or creditor, such as financial institutions. In developing countries, the main risk factors for the successful operation of PPP projects are the imperfect political and economic system, deficiency of laws, regulations and market mechanisms of the social capital's investment in infrastructure projects, low government credit, and high volatility of exchange rates and interest rates. Faced with high risks, government must reduce project risks by providing 
guarantees to realize the original intention of the PPP model and attract effective private investors' funds and technical services to public infrastructure projects.

Effective government guarantees can reduce the average charge rate of public infrastructure products and increase consumer utilization, thereby increasing consumer surplus and improving aggregate social welfare. Government guarantees in PPP projects aim at reducing risk and ensuring a certain level of income for investors. The toll collection of infrastructure projects is the only source of income, so a reasonable government guarantee can restrain the potential rise in user fees, which protects the consumer against price risk. However, guaranteed expenditures in government budgets are derived from the taxable income of consumers, which result in operational costs and possible negative impacts on socio-economic activities.

Government guarantees of PPP projects are presented in the following forms:

First, the minimal revenue guarantee (MRG). The concessionaire usually negotiates with government to provide a MRG to deal with deficit revenue risk. Under the minimum return guarantee, government is obliged to make up the difference between the minimum agreed level of revenue and the actual operating income of the concessionaire. Such a minimum guarantee can increase the willingness of a concessionaire to invest in PPP projects. Since such secured cash flows can provide a minimum level of debt coverage, the creditworthiness value of the PPP project can be increased in the face of high-yield risks.

Second, the minimum traffic/passenger flow volume guarantee. This guarantee is used in transport infrastructure projects where traffic/passenger flow volume is both the main source of revenue and the largest risk factor. Few projects are able to accurately predict traffic/passenger flow volume. In order to ensure benefits to the project company, the government and private sector will negotiate to determine a guarantee level of assurance dependent upon the forecast of the annual traffic/passenger flow volume. If the actual traffic volume per year is greater than or equal to the expected level, the government will not provide a subsidy; if it is less than the guaranteed level, government will compensate for difference between the actual volume of traffic and the secured traffic volume level.

Third, the guarantee for price adjustment. Infrastructure projects usually have a substantially long concession period, which typically increases the concessionaire's construction and operation costs due to rising inflation, labor, raw material and equipment costs. The guarantee for price adjustment is the government's commitment to the PPP project company allowing the company to adjust the user's price of infrastructure to reflect the changing situation during a specific period of time.

Fourth, the guarantee on debts. Loan guarantees include commitments given by government agencies or other public authorities, such as export credit agencies (ECAs) or multilateral organizations, to ensure that creditors' debt is recovered when the project company goes bankrupt. Sometimes, there is a commitment by government to take over the remaining debt of the project company after the project's concession period ends. The most obvious role of this guarantee is to improve confidence for banks and other financial institutions to provide project loans ensuring the successful implementation of the whole project.

Fifth, the maximum interest rate guarantee. This guarantee deals with volatile interest rates. Because this risk has a direct impact on a project company's financing costs and affects the project's future cash flow, government may provide a maximum interest rate guarantee in order to avoid an excessive burden on the project company due to uncontrollable interest rate increases.

Sixth, the guarantee on competition restrictions. This guarantee on competition restrictions is usually a commitment by the government that no PPP project of the same type will be approved for a certain period of time and in certain geographical area. For traffic highway projects, similar highway competition can seriously affect road traffic volume, adding an excessive income and profit risk to the project company.

Seventh, the government purchase guarantee. This kind of guarantee is less frequent in transport infrastructure projects and more common in sewage treatment and power plant projects. In order to ensure an adequate return to the project company, government will ensure that a certain number of products, generated by PPP projects, be purchased each year at the agreed price.

A government guarantee is not only a written commitment provided by the government, which essentially represents a certain intrinsic value, but it also has a tremendous impact on project incomes and government fiscal expenditures. Therefore, it is very necessary and important to assess the value of each government guarantee. In PPP projects, government provides the specific guarantee for the project company, so the level of the guarantee should match the associated commitment and risk level. Specifically, the level of government guarantees should match the at risk revenue with its project guarantee. The accurate value assessment of government guarantees is a necessary 
precondition for achieving reasonable risk-sharing.

Government guarantees for infrastructure projects are commitments that do not generate cash payments immediately but rather represent the government's obligation to pay for all future PPP project liabilities, which are contingent liabilities. If the potential risks of such contingent liabilities are not properly quantified and analyzed, they may place heavy burdens on government. A reasonable valuation of government guarantees not only allows government to determine the impact of future contingent liabilities on government budgets and deficits, but also allows the government to clearly define the level of each guarantee, ensuring that it is high enough to make the project economically viable, thereby avoiding an excessive burden on government.

\section{Fiscal Risk Management Issues of PPP Project Selection in China}

In 2013, the Central Government of China began promoting the PPP model. China's Ministry of Finance and National Development and Reform Commission have issued a substantial number of policies and regulations promoting PPP projects and have launched a number of demonstration projects and key development areas. The government policy documents that have been issued are closely related to fiscal risk control. Recently, the Ministry of Finance published guidelines on the operation of PPP projects and fiscal risk capacity as indicators of fiscal risk control. To strongly support PPP projects, many local governments have issued specific documents on project management and operational guidance, focusing on the scope of implementation, project processes, preferential policies, safeguard measures, and so on. However, most of these documents reflect only the principles of fiscal risk control and do not put forward specific problems in the operations, making it difficult to actually control fiscal risk.

Insufficient indicators on rigid conditions, such as fiscal risk control standards and punitive measures are the second fiscal risk management issue of PPP project selection in China. Provincial governments formulate rules and control the PPP projects' implementation. However, the existing government documents only specify the macroeconomic scope of the budgeted public expenditures. There is a lack of clear standards for potential PPP project risk, possible liability and the proportion of government's contingent liabilities.

Fiscal risk control, the third management issue, does not cover the entire life cycle of PPP projects, nor the project screening and demonstration phase. In this paper, we argue that fiscal risk controls must be carefully considered through the whole life cycle of the project. Currently, large-scale PPP projects are promoted in China and potential fiscal risks and losses arise if the preparatory work is insufficient. In particular, some projects are repurchased at a fixed income or interest rate by the government, so that the equity cooperation of the PPP project is actually converted into liabilities. In this situation, the PPP model is transformed into a debt financing instrument, which increases the government's debt-paying risk.

The fourth, de facto "dual management" of PPP projects by government departments, poses certain fiscal risk control and implementation obstacles for projects. PPP policy is basically promulgated by China's Ministry of Finance and by the National Development and Reform Commission. Each of these two national-level government departments require their own subordinate departments to separately implement policies and promote their subordinate departments to become the leading departments and regulatory authorities of a PPP project. Coordination within the system creates obstacles and causes problems for fiscal risk control.

In order to promote the development of PPP projects in China, the Chinese government takes advantage of its guarantee to protect each project's revenue sources, so as to avoid projects' demand risk. Government's support is a technically and economically feasible guarantee for PPP projects, which means that related costs and fiscal risks are confined within the scope of government's affordability. We therefore recommend that government utilize a more scientific approach than is currently in place, to select feasible PPP projects and ensure that government guarantees benefit the overall economy. Project selection should not be separate from project approval, but associated with relatively scientific and consistent standards to evaluate the benefits and risks of PPP projects, which will prevent government from excluding guarantees and subsidies on its balance sheet and avoid aggregate payment and significant fiscal risk ensuring the sustainable development of public finance. It is necessary to utilize the appropriate model to scientifically and prudently promote government guarantees for PPP projects. The following section develops and discusses the use of our simulation model to ensure socio-economic benefits of PPP projects.

\section{Methods and Models of PPP Project Selection}

Government's choice of a PPP project is a complex multi-objective decision involving many stakeholders. CCGP (chance-constrained goal-programming) can simulate optimal probability, under certain probability level with stochastic process, to provide objective criteria to improve government's PPP project decision making. In particular, government should ensure that its guarantees promote economic development, maintain fiscal stability and ensure 
the sustainability of PPP projects. In this paper, socio-economic net present value (SN) and financial net present value (FN) are the parameters of PPP investment projects. The economic welfare is taken into account in the former variable, while the latter is mainly measuring the profitability of a project's operation. Governments need to take into account the sustainability of government fiscal inputs and provide support to all economically viable. The fiscal sector acts as the "financial gatekeeper" and plays a role as the main agent of PPP project development. This section illustrates how to select a PPP project with the highest SN, the smallest FN change and the smallest government fiscal risk under the budget constraints.

A public investment department is always trying to find investment projects that are economically viable, regardless of whether government guarantees are provided or not, so the primary goal of government is to maximize the SN of each project with guarantees. This study assumes that all net present values have been calculated using a reliable method. In the CCGP framework, the objective function can be expressed as:

$$
\sum_{i=1}^{n} G_{i} S N_{i}-\vartheta_{S N}^{+}+\vartheta_{S N}^{-}=\sum_{i=1}^{n} S N_{i}
$$

If project $\mathrm{i}$ is the government-guaranteed project, then $\mathrm{Gi}=1$; otherwise $\mathrm{Gi}=0$, where $\mathrm{n}$ is the number of feasible projects and $\mathrm{SN}_{\mathrm{i}}$ represents the socio-economic net present value of each project. $\vartheta_{S N}^{+}$is the positive deviational variable of the expected target payment value and $\vartheta_{S N}^{-}$represents the negative deviational variable of the expected target payment value, both of which are the measurement of bias between the parameter value in the model and the target net present value, especially on the negative deviation.

The public sector has a public accountability obligation to minimize the cost of government guarantees or when the net present value of the total payment (GP) is at its minimum value:

$$
\sum_{i=1}^{n} G_{i} E\left(\widetilde{T}_{\mathrm{i}}\right)-\vartheta_{G P}^{+}+\vartheta_{G P}^{-}=\mathrm{GP}
$$

in which, $E\left(\widetilde{T}_{\mathrm{i}}\right)$ is the expectation of the present value of government guaranteed payments. $\vartheta_{G P}^{+}, \vartheta_{G P}^{-}$represent

the positive and negative deviations against the present value of the payments, respectively.

Equation (2) focuses on the minimization of government costs, while considering project revenue maximization. The objective of government guarantees is to ensure that each project proceeds with limited potential risks in order to achieve the optimal cost-benefit ratio of traditional public-invested projects. Another limitation of the model therefore, is that the FN of the project is the maximization of the value differences before and after the provision of government guarantees, with the following constraints:

$$
\sum_{\mathrm{i}=1}^{n}\left[E\left(\widetilde{F N_{\mathrm{i}}^{G}}\right)-E\left(\widetilde{F N_{\mathrm{i}}}\right)\right] G_{i}-\vartheta_{G}^{+}+\vartheta_{G}^{-}=\sum_{\mathrm{i}=1}^{n}\left[E\left(\widetilde{F N_{\mathrm{i}}^{G}}\right)-E\left(\widetilde{F N_{\mathrm{i}}}\right)\right]
$$

in which, $\left(\widetilde{F N_{\mathrm{i}}^{G}}\right), E\left(\widetilde{F N_{\mathrm{i}}}\right)$ represent the FN of each project with and without a government guarantee, respectively;

and $\vartheta_{G}^{+}, \vartheta_{G}^{-}$denote the positive and negative deviations from the FN of the project, respectively.

Theoretically, the government's fiscal risk in each PPP project can range from zero to infinity, the main reason of which is that annual government payments should be confined to the largest budget funds, so to denote fiscal risk in a mathematical way is more complex. First, the basic conditions of the fiscal risk control are:

$$
\mathrm{P}\left(\sum_{i=0}^{n} G_{i} \widetilde{T_{\mathrm{it}}}>B A R_{t}\right) \leq \gamma \text { for } t=1,2,3, \ldots, M
$$

in which P is the probability; $\widetilde{T_{\mathrm{it}}}$ is the actual amount of government guarantee paid for each period; BAR is the budget amount of government expenditure; $\gamma$ is the probability of over budget payment and $\mathrm{M}$ is the term of project. Following the principle of safety of public expenditure, Gauss inequality of random variables can be utilized, the expectation and variance of a government guarantee in each period can therefore be expressed as: 


$$
\begin{aligned}
& \mathrm{E}\left(\widetilde{T_{t}}\right)=\sum_{i=1}^{n} G_{i} E\left(\widetilde{T_{\mathrm{it}}}\right) \text { for } t=1,2,3 \ldots, M \\
& \left.\left.\sigma^{2}\left(\widetilde{T_{t}}\right)=\sum_{i=1}^{n} G_{i} \sigma^{2} \widetilde{T_{\mathrm{it}}}\right)+2 \sum_{i=1}^{n} \quad \sum_{j=1}^{n} G_{i t} G_{j t} \operatorname{coeffi} i_{G_{\mathrm{it}} G_{j t}} \sigma^{2} \widetilde{T_{\mathrm{it}}}\right) \sigma^{2}\left(\widetilde{T_{j t}}\right) \\
& \text { for } \mathrm{t}=1,2,3 \ldots \mathrm{M} ; \mathrm{i} \neq \mathrm{j} \\
& \mathrm{P}\left(\sum_{i=0}^{n} G_{i} \widetilde{T_{\mathrm{it}}}>B A R_{\mathrm{t}}\right) \leq\left\{\begin{array}{c}
\frac{4}{9 B A R_{\mathrm{t}}\left\{\left[\sum_{i=1}^{n} G_{\mathrm{i}} E\left(\widetilde{\mathrm{T}_{\mathrm{it}}}\right)\right]^{2}+\sum_{i=1}^{n} G_{i} E\left(\widetilde{\mathrm{T}_{\mathrm{it}}}\right)\right\}} \\
1-\frac{\mathrm{BAR}_{\mathrm{t}}}{\sqrt{3\left\{\left[\sum_{i=1}^{n} G_{\mathrm{i}} E\left(\widetilde{\mathrm{T}_{\mathrm{it}}}\right)\right]^{2}+\sum_{i=1}^{n} G_{\mathrm{i}} E\left(\widetilde{\mathrm{T}_{\mathrm{it}}}\right)\right\}}} \text { if } 0 \leq \mathrm{BAR}_{\mathrm{t}} \leq \theta
\end{array}\right.
\end{aligned}
$$

in which, $\theta=2 \sqrt{\frac{\left[\sum_{i=1}^{n} G_{i} E\left(\widetilde{T_{i t}}\right)\right]^{2}+\sum_{i=1}^{n} G_{i} E\left(\widetilde{T_{i t}}\right)}{3}}$

In the framework of CCGP, the right side of Equation (7) should be minimized and the expected value of each period obtained by using the specific distribution forms (i.e., normal, exponential, double exponential and Cauchy distribution). The actual performance of a PPP project is influenced by different variables, such as demand, tariffs, interest rates, exchange rates, construction costs, operation and maintenance costs, and so on. In addition, various variables are subject to a different distribution function, so the simulation based on the basic function becomes one of the effective analytical tools. The function of fiscal risk is assumed in the form of Cantelli inequality.

The final goal of each PPP project selection is to minimize the random variables of all "unintentional" variables. In this research, we adopt a weighted CCGP model. The weights are given by government decision makers according to the importance of different deviation variables. The objective function is:

$$
\operatorname{minV}=w_{S N} \vartheta_{S N}^{-}+w_{G P} \vartheta_{G P}^{+}+w_{G} \vartheta_{G}^{-}+\sum_{t=1}^{m} w_{T_{t}} \vartheta_{T_{t}}^{+}
$$

in which $w_{S N}, w_{G P}, w_{G}, w_{T_{t}}$ represent the respective relative weights of the various deviation variables.

The left-hand factor of the equation is divided by the corresponding target and the optimal function can be written as:

$$
\operatorname{minV} V^{\prime}=w_{S N} e_{S N}^{-}+w_{G P} e_{G P}^{+}+w_{G} e_{G}^{-}+\sum_{t=1}^{m} w_{T_{t}} e_{T_{t}}^{+}
$$

and the restrictive conditions are:

$$
\begin{gathered}
Q_{S N}-e_{S N}^{+}+e_{S N}^{-}=1 \\
Q_{G P}-e_{G P}^{+}+e_{G P}^{-}=1 \\
Q_{G}-e_{G}^{+}+e_{G}^{-}=1 \\
Q_{T_{t}}-e_{\tau_{t}}^{+}+e_{\tau_{t}}^{-}=1
\end{gathered}
$$

if $B A R_{t}>\theta$, for $\mathrm{t}=1,2,3, \ldots, \mathrm{M}$

\section{Simulation of the Optimal PPP Projects}

In order to test the applicability of the above-mentioned items, this section uses a relatively simple sample to test the model. In this section, 13 PPP demonstration projects, each with a government guarantee, are chosen from information published by China's Ministry of Finance. In the minimum government guarantee scheme, government will make up the difference if the actual income is lower than the minimum guaranteed value. In computation and analysis, the net present value of each item is analyzed with an average interest rate of $10 \%$ and the potential payment of a government guarantee is considered in the calculation of net present value. The equity-debt ratio is assumed to be $7 / 3$ for the typical capital structure of a comparable project in China. The model uses crystal ball software to carry out the Monte Carlo simulation with 1,200 iterations on the net present value of the project and the government guarantee expenditure. Table 1 depicts the value of the sample project's related variable. 
Table 1. Value of the related variables of sample PPP projects

\begin{tabular}{llllllllllllll}
\hline Project Number & $\mathbf{1}$ & $\mathbf{2}$ & $\mathbf{3}$ & $\mathbf{4}$ & $\mathbf{5}$ & $\mathbf{6}$ & $\mathbf{7}$ & $\mathbf{8}$ & $\mathbf{9}$ & $\mathbf{1 0}$ & $\mathbf{1 1}$ & $\mathbf{1 2}$ & $\mathbf{1 3}$ \\
\hline SN & 88.3 & 115 & 78 & 48 & 103 & 43 & 64 & 34 & 38 & 49.1 & 51 & 66 & 63 \\
\hline Change in FN & 1.64 & 2.6 & 1.2 & 0.5 & 1.2 & 1 & 0 & 0.9 & 1.1 & 0.63 & 0.8 & 0.9 & 0.6 \\
\hline Estimated Costs & 1.66 & 2.5 & 1.3 & 0.4 & 1.6 & 1 & 1 & 0.8 & 1.1 & 0.71 & 1.1 & 0.9 & 0.7 \\
\hline
\end{tabular}

The constraint function of the optimization problem in these sample cases contains 11 constraints with 14 variables and 22 deviations (refer to Appendix B). The Solver Add-In function in Excel $^{\circledR}$ is conducted to determine the optimal solutions. The result is that 8 of 13 sample projects belong to projects with a government guarantee, fiscal risk of which is controllable, namely projects $1,4,6,7,8,10,12$ and 13 .

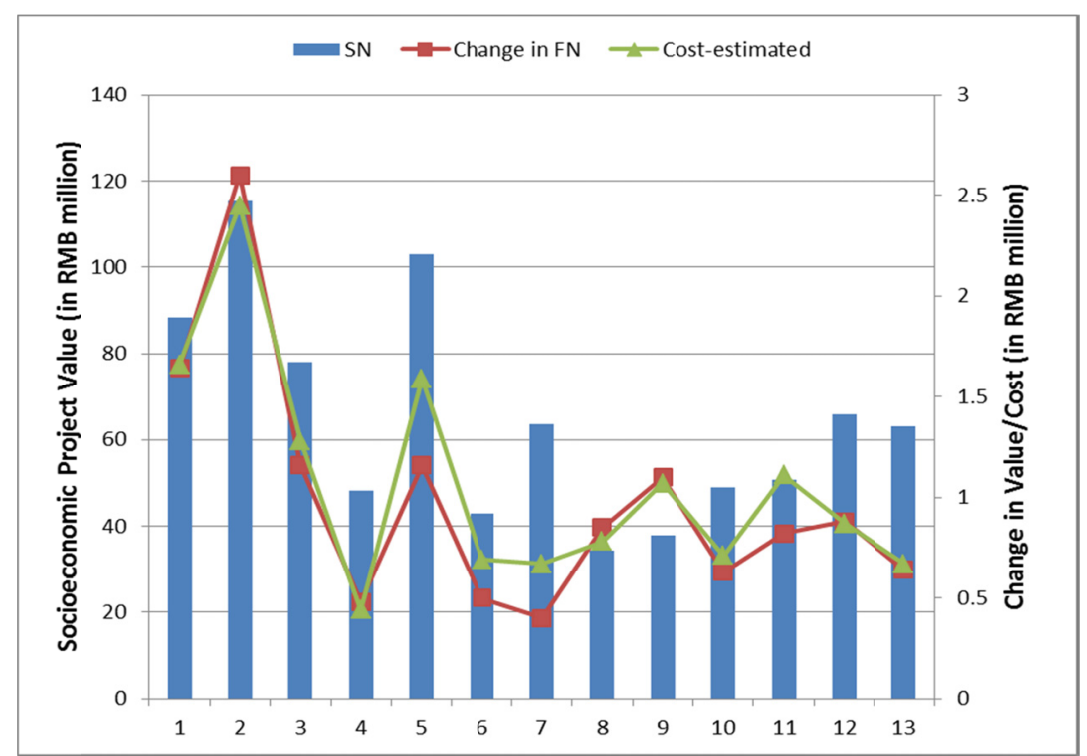

Figure 1. The effect of a government guarantee on the value of PPP projects

In addition, we carried out a Pareto optimality test of the project. Similar to the Pareto optimal state of public economics, the Pareto optimal state in public project risk management is defined as the risk-sharing parties who cannot improve their welfare or reduce their own welfare without harming other parties' welfare. In this model, the Pareto optimality test is to maximize the bias of "willingness" in the project, at least at the same level as the previous analysis (Wibowo \& Mohamed, 2010), or maximize the deviation under the same conditions within the system(refer to Appendix C).

$$
\min V^{\prime \prime}=w_{S N} e_{S N}^{-}+w_{G P} e_{G P}^{+}+w_{G} e_{G}^{-}+\sum_{t=1}^{m} w_{T_{t}} e_{T_{t}}^{+}
$$

the restrictive conditions are:

$$
\begin{gathered}
Q_{S N} \geq 0.399 ; Q_{G} \geq 0.442 ; Q_{G P} \leq 0.816 ; \\
Q_{T_{1}} \leq 0.591 ; Q_{T_{2}} \leq 0.731 ; Q_{T_{s}} \leq 0.825 ; \\
Q_{T_{4}} \leq 0.799 ; Q_{T_{s}} \leq 0.808 ; Q_{T_{s}} \leq 0.595 ; \\
Q_{T_{7}} \leq 0.374 ; Q_{T_{8}} \leq 0.655 ; Q_{T_{9}} \leq 0.519 ; Q_{T_{10}} \leq 0.34
\end{gathered}
$$


The results of the optimization test show that the previous optimization results are already Pareto optimal and no improvement can be made to increase the welfare of all parties. The benefits of each project have been maximized.

Our research suggests that the above methods require government officials be equipped with skills to identify and quantify the various risks implementing a PPP project, which will help the government clarify contingent liabilities for a government guarantee. All of these analytical tools require relevant personnel who have comprehensive knowledge in data research and an ability to solve related mathematical problems. The commercial software available on the market is only a general version for project evaluation, so we recommend that professionals be experts in handling risk-related variables and in problem-solving. It is necessary therefore, for government to invite relevant professionals and industry experts to join each project evaluation team.

\section{Conclusions and Policy Recommendations}

This paper focuses on the identification of appropriate tools for PPP project selection with contingent liabilities arising from China's government guarantees provision under government budget constraints. The choice of a PPP project is based on the importance of the project, risk situation, level of government acceptable risk, available budget size and the provision of government guarantees. In the framework of CCGP, this paper proposes the Monte Carlo simulation to aid project selection, establish various project scenarios, and compare the different benefits of projects with scenario analysis to ultimately choose the PPP project with best VFM. Therefore, government must address the implicit fiscal risk of PPP projects and take measures to control this fiscal risk.

First, a standard PPP project selection system should be established and continually reviewed. The appropriate PPP project selection requires long-term planning of public investment and utilizes VFM as the evaluation criteria for PPP projects. A cost-benefit analysis should be made in project evaluation technology to determine the investment value and significance of PPP projects. Benchmark values should be established for public investment and the possibilities of achieving VFM of the projects estimated. The United Kingdom introduced the "Guide for VFM assessment" in 1999 and an updated version in 2004. At the time of this writing, there is no specific operation manual to determine the feasibility of PPP projects in China. The main function of project screening is to eliminate projects unsuitable for the PPP model. Fundamental errors during the screening and follow-up operations may lead to a series of issues, such as the failure of a project and conflicts between the public and private sectors that will substantially increase government's risk. It is necessary to establish a VFM assessment procedure for PPP projects prior to project initiation. This can be done either by the public sector or by an independent third party. Those projects that have not passed the VFM assessment should not be approved under the PPP model.

Second, it is prudent to determine the scope of government guarantees and establish an optimal risk-sharing model. The control mechanism design, based on the whole project process, is an important precondition to effectively reduce fiscal risk. And four distinctive types of government responsibilities should be clarified in the PPP project life cycle. Process supervision of PPP projects can be broadly divided into four major parts: project screening and feasibility studies, auditing of the access entity, operation performance monitoring, and project termination supervision. Among them, the project screening and feasibility studies is the main gatekeeper, which determines whether a project is suitable to utilize the PPP construction model.

Risk sharing of PPP projects usually follows two major principles: Initially, risks should be allocated to the public or private sectors based on their comparative advantages in risk-taking. Then, the risk-sharing should be compatible with the potential benefits. A detailed risk-sharing matrix should therefore be developed for each PPP project and a reasonable allocation of risk between the public and private sectors implemented in each project contract, which will effectively manage government's fiscal risk. It is necessary to design special methods to control government's discreditable behavior in PPP project selection including minimum demand risk, project contract termination risk and non-compliance risk. The local government must be involved in the project as a stakeholder with the provision of land or other intangible assets.

Third, the status of each PPP project should be clarified within the government budget. It is important that government avoid the conversion of contingent liabilities of a PPP project to real government debt and that government's responsibility for fund expenditures in PPP projects also be clarified. The total amount of fiscal expenditure in PPP projects should be pre-determined, which can attract more social capital. In addition, the size of PPP projects should link to the local government funds' budget emphasizing the overall control of local government debt, especially those regions with greater potential fiscal risk. Regulators should pose special requests for high-risk areas, reflecting the ideas of differentiated treatment and specific control.

Fourth, government should improve budget and evaluation disclosure systems related to fiscal risk. If the PPP 
project's financial expenditure funds are listed in the budget, the local governments must follow this hard constraint, which will help reduce the doubts of social capital and attract social capital investment in infrastructure projects. From the point of view of project management, government should publish standard formula to calculate project proceeds for the reference of local government, social capital, financial institutions and other stakeholders. The information disclosure requirements are conducive to make PPP projects more transparent, which will receive increased supervision from the public sector and prohibit various non-standard behaviors during the PPP project development process.

Fifth, we conclude that reform of the government accounting system, with adaption to the PPP model, should be promoted. Government should strengthen the response and rolling-cost budget system on government debt. To establish an accrual based government accounting and reporting system, government must measure its contingent liabilities, take the responsibility to report various types of government information, and analyze direct and contingent public debts on a continuous basis.

Sixth, and finally, our research shows that it is in China's best interest to establish systematic policies and regulations to improve PPP project management, including system evaluation, guidelines for standard documents, and so on. In addition to the supporting systems, integrity and contract culture play an extremely important role in the development of PPP projects. The life cycle of PPP projects is usually longer than regular public projects and astride multiple successive administrations. PPP projects may therefore encounter changes in policies and regulations. Cultivating a culture of integrity and contract spirit is particularly significant.

\section{Acknowledgments}

The research is sponsored by the Philosophy and Social Science Research Fund (GD15XYJ14) of Guangdong Province, China.

\section{References}

Akitoby, B., Hemming, R., \& Schwartz, G. (2007). Public Investment and Public Private Partnerships. International Monetary Fund.

Budapest, H. (2006). PPP and Fiscal Risks Experiences from Portugal. International Monetary Fund Working Paper. $2-4$.

Cheung, E., \& Chan, A.P.C. (2011). Risk factors of Public-Private Partnership projects in China: comparison between the water, power, and transportation sectors. Journal of Urban Planning and Development, 137(4), 409-415. https://doi.org/10.1061/(ASCE)UP.1943-5444.0000086

Feng, Z., Zhang, S., \& Gao, Y. (2015). Modeling the impact of government guarantees on toll charge, road quality and capacity for Build-Operate-Transfer (BOT) road projects. Transportation Research. Part A: Policy and Practice, 5(6), 54-67.

Hu, Z., Fan, X.Q., \& Dong, Q. (2012). Decision-making model of public-private partnerships projects' paradigm choice-based upon the SVM classified theory. Journal of Xi'an Univ. of Architecture Technology (Natural Science Edition), 44(4), 568-571. (in Chinese)

Ke, Y.J., Wang, S.Q., \& Chan, A.P.C. (2010). Risk allocation in Public-Private Partnership infrastructure projects: comparative study. Journal of Infrastructure System, 16(4), 343-351.

Liu, J., Yu, X., \& Cheah, C. (2014). Evaluation of restrictive competition in PPP projects using real option approach. International Journal of Project Management, (7), 473-481. https://doi.org/10.1016/j.jproman.2013.07.007

Ministry of Finance (MoF) China. (2014). Experience from Asian Development Bank in applying PPP model and Suggestions. China State Finance, 9, 18-19. (in Chinese)

Nugroho, L. (2015). Franchise Revenue Guarantee Valuation: Real Options Approach. Journal of Financial Risk Management, (4), 26-39. https://doi.org/10.4236/jfrm.2015.41004

Shen, L.Y., Platten, A., \& Deng, X.P. (2006). Role of public private partnerships to manage risks in public sector projects in Hong Kong. International Journal of Project Management, 24(3), 587-594. https://doi.org/10.1016/j.ijproman.2006.07.006

Wibowo, A., \& Kochendoerfer, B. (2011). Selecting BOT/PPP Infrastructure Projects for Government Guarantee Portfolio under Conditions of Budget and Risk in the Indonesian Context. Journal Construction Engineering Management, 12(10), 512-522. https://doi.org/10.1061/(ASCE)CO.1943-7862.0000312 
Wibowo, A., \& Mohamed, S. (2010). Risk criticality and allocation in privatized water supply projects in Indonesia. International Journal of Project Management, 28(5), 504-513. https://doi.org/10.1016/j.ijproman.2009.08.003

Wibowo, A., \& Wilhelm Alfen, H. (2014). Identifying macro-environmental critical success factors and key areas for improvement to promote public-private partnerships in infrastructure. Engineering, Construction and Architectural Management, 78(8), 383-402. https://doi.org/10.1108/ECAM-08-2013-0078

Yuan, J., Chan, A., Xiong, W., Skibniewski, M., \& Li, Q. (2013). Perception of Residual Value Risk in Public Private Partnership Projects: Critical Review. Journal of Management in Engineering.

Yuan, J.F., Skibniewski, M.J., Li, Q.M., \& Shan, J. (2010). The driving factors of China's Public-Private Partnership projects in metropolitan transportation systems: public sector's viewpoint. Journal of Civil Engineering Management, 16(1), 5-18. https://doi.org/10.3846/jcem.2010.01

Zhang, S., Chan, Albert P.C., Feng, Y.B., Duan, H.X., \& Ke, Y.J. (2016). Critical review on PPP Research - A search from the Chinese and International Journals. International Journal of Project Management, (4), 597-612. https://doi.org/10.1016/j.ijproman.2016.02.008

\section{Appendix A.}

The fiscal risk constraint, Equation (4) can be rewritten as:

$$
\mathrm{P}\left[\sum_{i=1}^{n} G_{i}{\widetilde{T_{i t}}}^{-\widetilde{B A R}_{t}}+E\left(\widetilde{B A R_{t}}\right)>E\left({\widetilde{B A R_{t}}}_{t}\right)\right] \leq \gamma
$$

The independent variables can be expressed as:

$$
\begin{gathered}
\mathrm{E}\left(\widetilde{R_{t}}\right)=\sum_{i=1}^{n} G_{i} E\left(\widetilde{B A \bar{R}_{t}}\right) \\
\sigma^{2}\left(\widetilde{R_{t}}\right)=\sum_{i=1}^{n} G_{i}^{2} \sigma^{2}\left(\widetilde{T_{i t}}\right)+\sigma^{2}\left(\widetilde{B A R_{t}}\right)
\end{gathered}
$$

According to the principle of safety and simplicity, this derivation applies the Cantelli inequality and the result can be used in the fiscal risk control system of this research:

$$
\mathrm{P}\left[\widetilde{R_{t}}>E\left(\widetilde{B A R_{t}}\right)\right] \leq \frac{1}{1-\left[\frac{E\left(B \widetilde{A R} T_{t}\right)-E\left(\widetilde{R}_{t}\right)}{\sigma^{2}\left(\widetilde{R_{t}}\right)}\right]^{2}}
$$

\section{Appendix B.}

$$
\begin{aligned}
& \operatorname{minV}=4.25 e_{S N}^{-}+3.4 e_{G P}^{+}+2.55 e_{G}^{-}+e_{T_{1}}^{+}+0.8 e_{T_{2}}^{+}+0.76 e_{T_{\mathrm{s}}}^{+}+0.72 e_{T_{4}}^{+}+0.68 e_{T_{5}}^{+}+ \\
& 0.64 e_{T_{6}}^{+}+0.6 e_{T_{y}}^{+}+0.55 e_{T_{8}}^{+}+0.51 e_{T_{9}}^{+}+0.47 e_{T_{10}}^{+}
\end{aligned}
$$


Appendix C.

Guarantee Flow Diagram:

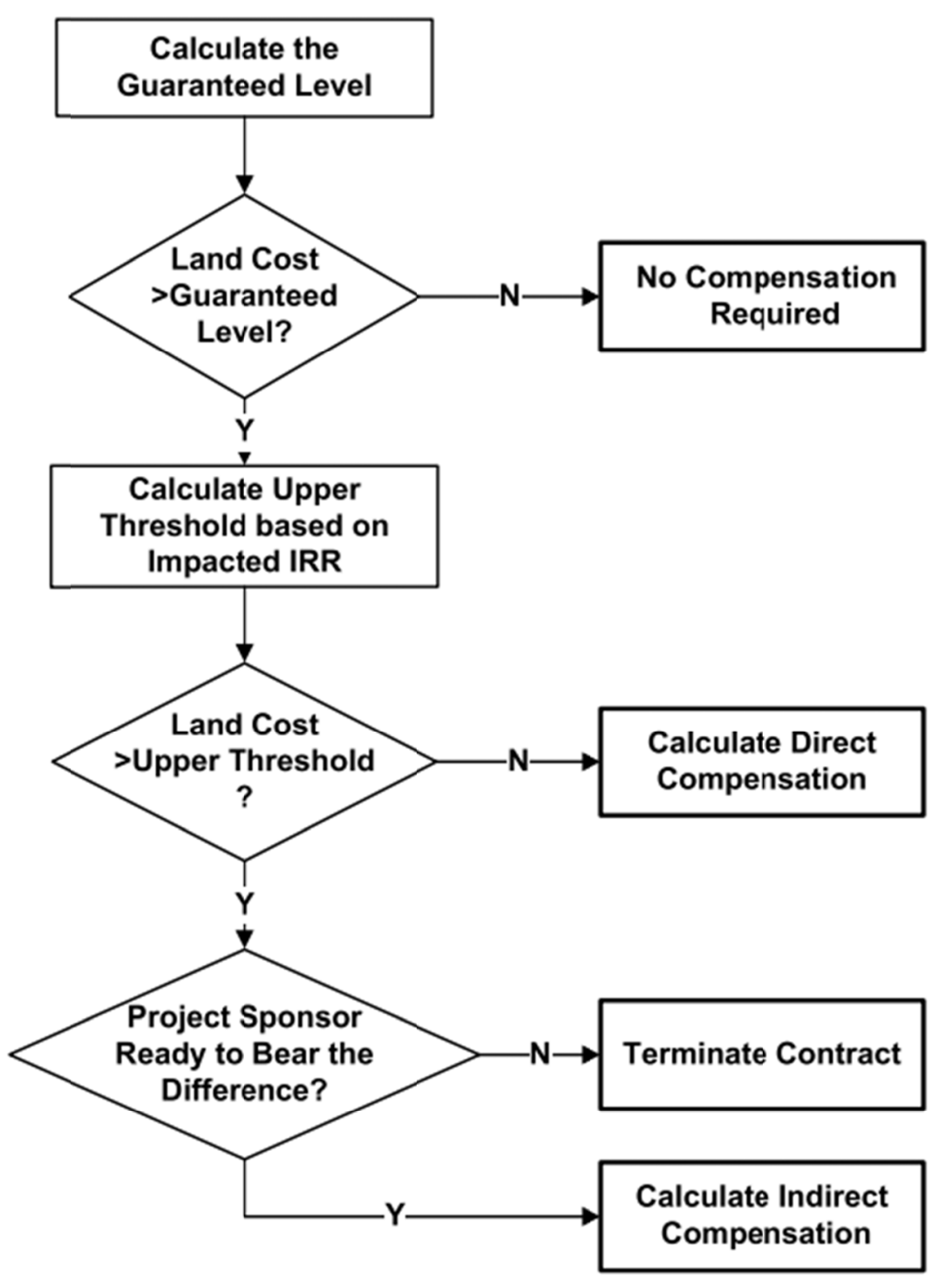


Binomial Tree-Like Diagram of Projects for Public Services:

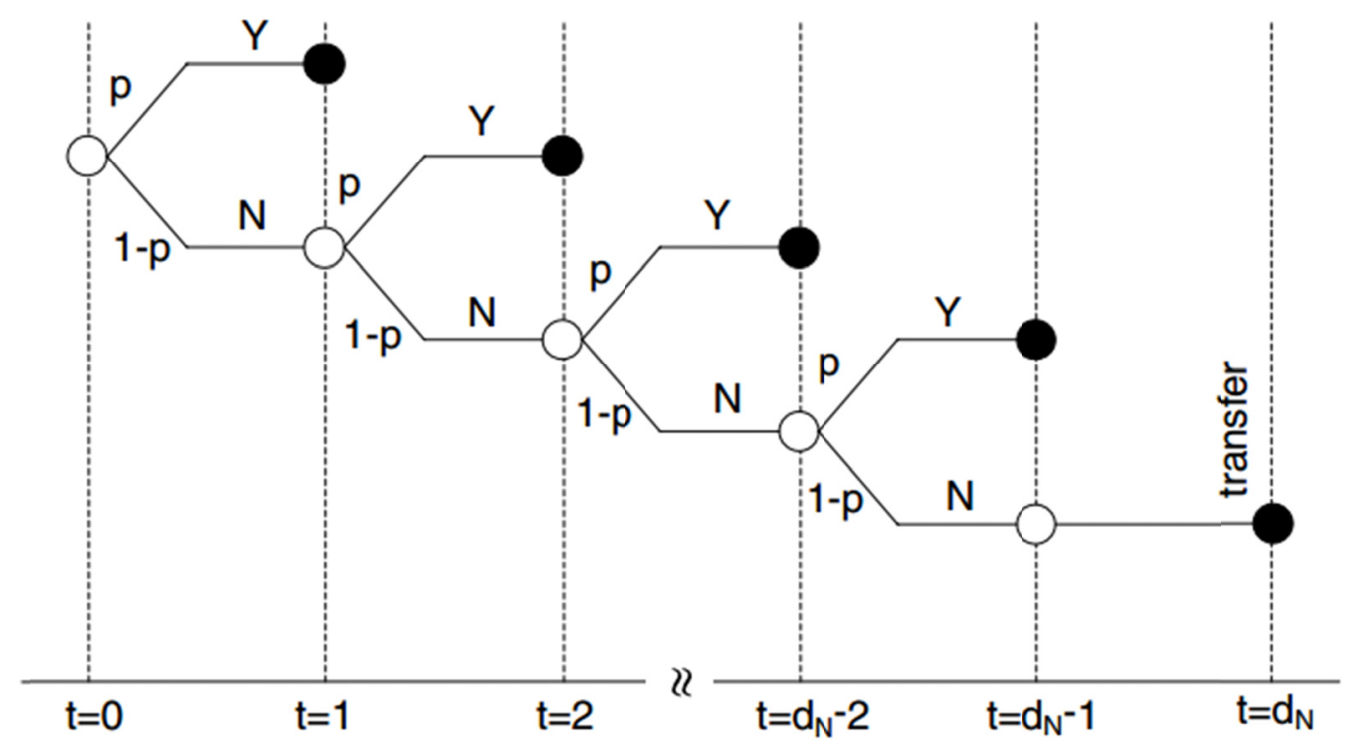

Sample Window for Iteration:

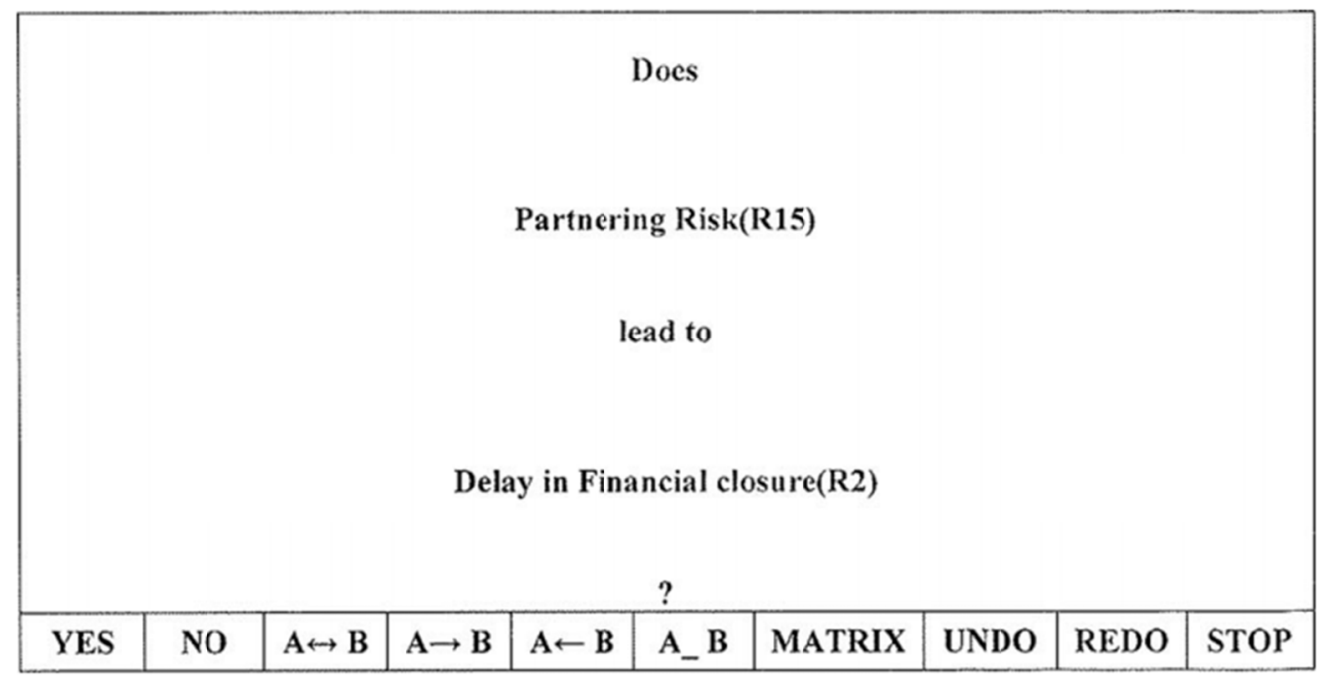

